\title{
TRAJETÓRIA FORMATIVA E PRÁTICA DOCENTE DE PROFESSORES DE GEOGRAFIA EM JOÃO PESSOA (PB)
}

\author{
THE FORMATIVE TRAJECTORY AND TEACHER'S PRACTICE OF TEACHERS IN \\ JOÃO PESSOA (PB)
}

\author{
TRAYECTORIA DE LA FORMACÍON Y PRÁCTICA DE ENSINO DE MAESTROS \\ DE GEOGRAFÍA EN JOÃO PESSOA (PB)
}

\author{
Antonio Carlos Pinheiro - Universidade Federal da Paraíba - João Pessoa - Paraíba- Brasil \\ antoniocarlçospinheiro@uol.com.br
}

\section{Resumo}

Esse artigo é parte de uma investigação realizada com professores do ensino fundamental na Paraíba, entre 2012 e 2014. 0 problema relaciona-se ao controle do tempo-espaço escolar e da aprendizagem, exercida pelo professor e condicionada por uma permanência de práticas tradicionais que dificultam a flexibilização curricular. Embora existam várias propostas inovadoras no cotidiano da escola na atualidade, o controle do tempo-espaço e da aprendizagem promove pouca autonomia para ensinar e aprender entre professores e alunos. A Metodologia Autobiográfica foi utilizada na pesquisa, em especial, a modalidade História de Vida, com o objetivo de conhecer a formação escolar e acadêmica para refletir sobre a prática docente atual por meio do relato dos professores. 0 objeto de estudo são as suas narrativas.

Palavras-chave: ensino de Geografia, prática docente, História de Vida.

\begin{abstract}
This textispart of aresearch conductedwithteachers who work in elementary schools in the Paraíba, in 2012 and 2014. The problem isrelatedto the controlof school time-space and learning and it is practiced by teachersand conditionedby apermanence of traditionalpractices thatcomplicate thecurricular flexibility. Itis observed thatalthough there areseveralinnovative proposalsin the school routineat present, thecontrol of time-space and learningpromote little autonomytoteaching and learningbetween teachers and students. Theautobiographicalmethodologywas usedin this research, in particularthe mode ofhistory of life, aiming toknow theschoolandacademic educationto reflecton currentteaching practicethroughout the reports from theteachers. The objectof study isthe narratives from theteachers who workin elementary schools.

Key words: Teaching of Geography, Teaching Practice, History of Life.
\end{abstract}

\section{Resumen}

Este articulo esproducto de una investigaciónconprofesores que trabajanenlaeducación primaria en Paraíba, en 2012 y 2014. El problema se relaciona conelcontroldeltiempo-espacio y de elaprendizaje, ejercida por elprofesor y condicionada por diversas prácticastradicionales que dificultanlaflexibilidad curricular; conesto, se observa que aunqueexistanpropuestasinnovadorasenel cotidiano de laescuela, enlarealidad, elcontroldeltiempoespaciopromuevepocaautonomía para laenseñanza y elaprendizaje entre maestros y alumnos. La metodología autobiográfica usada enlainvestigación, es lamodalidad de historia de vida, conel objetivo de conocerlaformación escolar y académico para reflexionar sobre lapráctica docente actual de los maestros. El objeto de estudiosonlasnarraciones de los docentes que trabajanenlaescuela básica.

Palabras clave: enseñanza de la Geografía, práctica pedagógica, Historia de Vida. 
Introdução

O presente artigo é parte de investigações realizadas entre 2012 e 2014 na UFPB, com doze professores da escola básica na cidade de João Pessoa (PB). O problema relaciona-se ao controle do tempo-espaço escolar e da aprendizagem, exercida pelo professor e condicionada por uma permanência de práticas tradicionais que dificultam a flexibilidade curricular; observa-se que, embora existam na atualidade várias propostas inovadoras no cotidiano escolar, o controle do tempo-espaço e da aprendizagem promove pouca autonomia para ensinar e aprender entre professores e alunos.

Na pesquisa, utilizou-se a Metodologia Autobiográfica, em especial a modalidade de História de Vida, por meio do relato dos professores, com o objetivo de conhecer a formação escolar e acadêmica para refletir sobre a prática docente atual. O objeto de estudo são as narrativas desses profissionais que atuam no ensino fundamental. Como procedimento metodológico, a História de Vida permite refletir sobre experiências construídas em suas práticas de vida e, a partir delas, pode-se identificar o contato com o ensino de Geografia: o aprendido e o ensinado.

Conhecer a trajetória escolar dos professores, sua autobiografia, é fundamental para entender os processos de socialização profissional que acontecem nas escolas. Acredita-se que, na formação em serviço e na vivência escolar, internalizam modelos de ensino, saberes e regras, comportamentos que resultam em práticas docentes, sobretudo nos primeiros anos de trabalho. As questões propostas para eles permitiram a reflexão sobre suas experiências atuais.

Trabalhamos com doze professores, todos naturais da Paraíba - três do sexo masculino e nove do sexo feminino -, com idade entre 23 e 51 anos: cinco têm de 23 a 30 anos; dois de 30 a 40 anos; e quatro têm mais de 40 anos. Apesar da diferença de idade entre eles, todos são formados recentemente, com menos de 10 anos de atuação. Dos doze professores, onze fizeram o curso em universidade pública e uma formou-se em curso à distância. Neste artigo, são usados nomes fictícios para representá-los: Amanda-24, Camila-23, Cecília-47, Eduardo-29, Fernando-48, Francisco-29, Jaqueline-29, Lucia-37, Maria-43, Paula-32, Sandra-25 e Vanda-51. Para apoiar a reflexão sobre o tema deste artigo, há trechos dos relatos de alguns professores, com a sua referida identificação: o primeiro nome 
de cada um e a idade que tinha no momento da entrevista; por exemplo (Amanda-24).

\section{A educação escolar como modelo organizacional hegemônico}

Lana Cavalcanti (2010) faz uma distinção entre a geografia ensinada na escola e a geografia produzida na universidade. Para ela, a geografia escolar tem uma estruturação própria; não se trata de uma simples transposição da ciência geográfica para o ensino básico. Porém, como a ciência geográfica atua como importante referência na organização curricular da escola básica, segundo a autora, é pertinente e relevante discutir as abordagens da geografia escolar em sua relação com as concepções teórico-metodológicas da geografia acadêmica (Cavalcanti, 2010). Se existe uma geografia engendrada no interior da escola, é possível identificar uma epistemologia própria?

Para Capel (1999), a constituição e a institucionalização de uma disciplina como ciência se dão por um conjunto de fatores. Entre eles, destacam-se a organização da comunidade a qual pertence a disciplina, a sua demarcação de atuação no rol de outras áreas e a possibilidade de sua profissionalização. Capel (1999) ressalta que o geógrafo já trabalhava para o Estado numa época em que havia poucos investimentos na ciência como força produtiva. No caso da Geografia, isso ocorre desde o século XVIII até o século XIX. Considerando o vasto campo de atuação do geógrafo, que envolve desde a organização do espaço terrestre até as inúmeras relações existentes nesse espaço, ficou constatado que, para esse profissional, existe uma ampla área de atuação. No século XIX, o movimento do conhecimento estava caminhando para a especialização das disciplinas, definindo métodos e objetos de investigação. Enquanto área de conhecimento, a Geografia produzia um interesse especial para outras comunidades, mas especialmente para o Estado, como estratégia para conhecer o território. Outro interesse sobre a Geografia também era sua potencialidade como matéria de ensino para integrar o currículo escolar à formação da mentalidade em consonância com a constituição dos Estados-nacionais e da modernização industrial da época.

No caso do Brasil, segundo Vlach (2006), é notória a inclusão no currículo escolar, no final do século XIX, da geografia e da história como matéria de ensino, tendo como uns dos atributos principais fomentar e 
formar nos alunos a ideia de nação. Na década de 1930, com a expansão das escolas para a maioria das regiões do país, o ensino de Geografia se firma no currículo escolar. Desde tempos remotos, os currículos de Geografia aparecem organizados nos materiais didáticos por meio de temas como: relevo, vegetação, hidrografia, população, economia etc. Apesar de vários movimentos de renovação da Geografia, do ensino e de novos materiais didáticos, esse modelo atravessou o século XIX, prevalecendo na prática de muitos professores e no imaginário social sobre essa matéria de ensino, até os dias atuais, um padrão de abordagem. Embora haja aproximações entre o modelo organizacional da escola básica com o ensino superior, essa organização curricular tem mais força no ensino escolar. É possível que nessas reflexões encontrem-se indícios para explicar a existência de uma Geografia genuinamente escolar?

As discussões sobre a importância da organização curricular na escola básica de forma sistemática é recente, sobretudo em comparação com a idade da própria escola. De acordo com Canário (2006), o modelo escolar atual data do final do século XVIII, quando se institucionaliza um padrão que passa a monopolizar a educação, o ensino e a socialização das pessoas, tornando-a hegemônica. Desde essa época, as práticas pedagógicas e a organização do tempo-espaço ocuparam professores e outros pensadores na busca de normatizações que pudessem garantir um funcionamento ideal da escola por meio da internalização de uma ordem disciplinar, pensando-a desde a organização do conhecimento, passando pelo controle do corpo e dos comportamentos, até a regumentalização do tempo-espaço escolar. Desde então, construiu-se uma naturalização da organização escolar, evoluindo para um modelo tendo por base "uma compartimentação estandardizada dos tempos (aula de uma hora), dos espaços (sala de aula), do agrupamento dos alunos (turma) e dos saberes (disciplinas)" (Canário, 2006, p. 15). Para o autor, esse modelo escolar prevaleceu influenciando a divisão do trabalho do professor e de sua prática docente.

Paulo Freire, no livro Pedagogia do oprimido, ao definir a concepção bancária da educação - modelo em que o educando é tratado como mero receptáculo -, caracteriza as relações educadores-educandos como narradoras ou dissertadoras. A simples narração de conteúdos, como explica Freire (1983, p. 65), tende a "petrificar-se ou fazer-se algo quase morto". Narrar o conteúdo sobre algo sem interconexão entre os sujeitos e com a realidade do mundo concreto pode levar os educandos a crer que 
essa realidade é algo "parado, estático, compartimentado e bem comportado” (p. 65). Por essa prática, o narrador (edudador) é o agente primordial da relação, cuja tarefa é introduzir nos educandos (receptáculo), conteúdos fragmentados da realidade, "desconectados da totalidade em que se engendram e em cuja visão ganharia significação” (p. 65). Esse modelo de narração-dissertação torna a palavra sem significação, descontextualizada; portanto, para Paulo Freire, seria melhor não dizê-la.

Assim como Paulo Freire, vários educadores, a partir da década de 1960, passaram a criticar o modelo hegemônico escolar, buscando outras formas para superá-lo. Dentre eles, destaca-se o livro de Bordieu e Passeron (1992), A reprodução, que considera a ação pedagógica como uma violência simbólica, pois reproduz práticas, por meio da internalização, subservientes nos educandos, naturalizando o modelo de divisão de classes e dificultando desvendar essa realidade. Essas práticas eram dirigidas para as classes populares, por meio de uma estrutura que pregava a estabilidade social e a manutenção da ordem. O modelo escolar vigente e sua organização curricular, segundo essa visão, eram concebidos para alunos provenientes da classe média, o que dificultava a escolarização das crianças e dos jovens das classes populares. Para Bordieu e Passeron (1992), a ação pedagógica do modelo hegemônico da escola se dava a partir da comunicação, porém não era apenas uma simples relação de comunicação, mas uma ação condicionada por padrões sociais numa formação social determinada, considerada como referência a cultura legítima, ou seja

a cultura dotada da legitimidade dominante não é outra coisa que o arbitrário dominante, na medida em que ele é desconhecido em sua verdade objetiva de arbitrário cultural e de arbitrário cultural dominante”. (1992, p. 36)

Sobre arbitrário cultural, compreende-se que os autores se referem ao fato de que não existe uma cultura superior a outra, mas uma hierarquia de sobreposição; assim, o conjunto de valores e significados que constitui um complexo cultural é arbitrário, ou seja, não está assentado em uma razão objetiva. Cada grupo constrói a sua cultura e é possível que ele confira para sua cultura tal legitimidade a ponto de elegê-la como a única possível e verdadeira. Boudieu e Passeron (1992) afirmam que a cultura transmitida pelo modelo da escola oficial é a cultura legitimada pelas classes dominantes, considerada superior a todas as outras. Desse modo, a 
escola, considerada autoridade pedagógica, por meio de suas ações, oculta uma parcialidade, transmite em caráter arbitrário um modelo cultural em detrimento de outros, exercendo um poder cultural. Na prática, a forma e os conteúdos trabalhados pouco atendem às necessidades da maioria da população, uma vez que preservam um padrão cultural. Com isso, promovem a exclusão de parte das pessoas que não consegue se adaptar ao modelo escolar vigente, por não encontrar nele sentido para sua vida cotidiana. Bordieu e Passeron (1992) afirmam também que a valorização de um arbitrário cultural em detrimento de outro gera a legitimidade da exclusão de um sobre o outro, impondo para aquele subjulgado um ensino de segunda categoria, já que o trabalho pedagógico encaminha o sujeito para uma exclusão legitimada sob a forma de autoexclusão. Essa violência simbólica é inculcada e aceita, muitas vezes sem questionamentos, pelos educandos e educadores que, embora sejam partícipes da autoridade pedagógica (professores, gestores educacionais), reproduzem essa organização escolar como um modelo ideal. A cultura consagrada influencia a organização curricular na abordagem dos conteúdos, nos procedimentos didáticos, tendo como referência essa cultura legitimada. Sobre esse entendimento, Lopes e Macedo (2011, p. 28) afirmam que "a reprodução cultural opera de forma semelhante à reprodução econômica: o capital cultural das classes médias, desigualmente distribuído, favorece aqueles que o possuem e, com isso, perpetua a desigualdade dessa distribuição".

Diante dessas posições, é possível fazer um paralelo e retomar Paulo Freire na sua definição de educação libertadora quando propõe uma prática problematizadora que considere o educando como um ser no e com o mundo. Nessa perspectiva, o educador deve romper com o modelo vertical de hierarquia da escola tradicional, estabelecer a prática do diálogo e da intercomunicação, superando o papel de apenas transmissor do conhecimento.

Em relação aos professores pesquisados, nota-se que a maioria vivenciou um ensino baseado no modelo tradicional. O professor Eduardo-29, por exemplo, relatou que durante sua formação na escola básica, sua professora de geografia valorizava o conteúdo e usava métodos punitivos para conduzir a matéria, exercia a sua violência simbólica por meio de narração de fatos pessoais: “[...] vez ou outra ela contava histórias sobre sua fase escolar na infância e como se deu conta da importância dos estudos”. Segundo o depoimento de Eduardo, por meio das histórias, a pro- 
fessora controlava os alunos. Elas eram uma estratégia usada para manter os alunos integrados às regras da escola, eram utilizadas para reforçar a ideologia dominante.

A professora Maria-43 contou que nasceu numa família pobre, considera que muitos dos seus problemas escolares estavam relacionados com sua condição econômica e com sua cor. Para ela, ser negra numa escola onde a maioria era formada de brancos deixava-a vulnerável:

A menina que adorava estudar passou a odiar a escola. A professora - se assim posso chamá-la - não gostava de mim. Ela me maltratava com palavras, como eu não podia respondê-la, pois criança educada não responde aos mais velhos, principalmente a professora a "dona do saber" afinal eu era educada para isso e sofria calada.

Segundo Maria, sua desilusão com a escola começou com sua formação na escola básica, tinha muitas dúvidas sobre o que era ensinado, mas raramente perguntava porque não se sentia à vontade. A trajetória de Maria foi bastante conturbada. Para ela, muito do que aprendeu não foi significativo, pois além do preconceito que sofreu, não via sentido em quase nada, sobre a geografia declarou: "lembro pouco, tinha que decorar muitos questionários, mapas, regiões, cidades, rios para fazer provas, isso era um pesadelo para mim e por causa disso também piorou a minha situação nos estudos”.

\section{As Políticas Curriculares Nacionais na visão dos professores}

Na pesquisa, trabalhamos com professores do ensino fundamental; portanto, as referências são os Parâmetros Curriculares Nacionais para o Ensino Fundamental (PCNEF), mas neste texto será usado apenas PCN. Este documento está dividido em quatro ciclos para os nove anos do ensino fundamental e as propostas temáticas estão articuladas pelos seguintes conceitos: espaço, lugar, paisagem, território e região. Os objetivos são construir competências e habilidades; do ponto de vista teórico, o documento não adota nenhuma linha específica da geografia, caracteriza-se por um ecletismo metodológico (Nunes, 2012).

Acerca dos PCN, todos os professores afirmam que conhecem, porém poucos conseguem fazer uma análise da proposta pedagógica, em especial sobre o sentido dado às competências e habilidades. Dos 12 pro- 
fessores, apenas a metade consegue diferenciar umas das outras e sobre como usam os PCN para organizar seus planos de trabalhos, todos afirmam que têm no documento a sua referência. O professor Eduardo-29 afirma:

Hoje em dia se pode contar com o apoio dos Parâmetros Curriculares para auxiliar no planejamento das aulas, diferente da minha época que os estudos eram precedidos de memorização e descrição, não havia nenhuma associação com a nossa realidade. Agora é diferente, não há desculpas para um mau planejamento.

A maioria dos professores considera a proposta positiva e a utiliza como fonte de pesquisa na elaboração dos seus planos de cursos, porém muitos o fazem sem questionar seus aspectos teóricos, centram seus comentários nos procedimentos metodológicos, como se observa no depoimento de Sandra-25:

Este documento possui como pressuposto a busca da metodologia adequada ao contexto local do aluno. Um professor ao elaborar seu plano de aula necessita ter claro no planejamento qual percurso metodológico utilizar, especialmente, a partir do trabalho com o espaço e o tempo, categorias que podem ser desenvolvidas desde os primeiros anos do ensino fundamental e não prender-se ao livro didático.

Alguns professores consideram que muitos livros didáticos que chegam à escola, por meio do Plano Nacional do Livro Didático (PNLD), estão baseados inteiramente nos PCN. A maioria revelou que não existe na escola a prática de discutir os PCN; em geral, durante as reuniões as discussões se referem aos problemas cotidianos dos alunos, aos resultados de avaliações e às questões administrativas da escola. Porém, a maioria considera que a contribuição mais significativa que os PCN proporcionaram foi propor a elaboração de atividades diferenciadas, entender melhor a geografia a ser ensinada e valorizar o conhecimento prévio dos alunos. Para Amanda-24,

anteriormente o lugar e a região eram sempre vistos como dimensões objetivas resultantes das interações entre o homem e a natureza. Atualmente, a categoria de lugar, assim como a de paisagem estão sendo recuperadas pela nova geografia, em uma nova dimensão. Nos PCN, o lugar deixou de ser simplesmente o espaço em que ocorrem interações entre o homem e a natureza para incorporar as 
representações simbólicas que constroem juntamente com a materialidade dos lugares, e com as quais também interagem.

Desde a promulgação dos PCN, existem várias críticas ao documento e a mais significativa delas é a forma como ele foi elaborado e encaminhado para os professores. Para Nunes (2012, p. 96), um dos problemas da pouca compreensão pelos professores dos aspectos teóricos presentes nos PCN reside

no caráter autoritário e centralizador da proposta, na medida em que, em seu processo de elaboração, houve pouco debate e participação dos professores do ensino fundamental, os principais agentes do processo educacional. A partir do processo de elaboração ficou implícita uma concepção de professor como mero executor de tarefas, incapaz de formular propostas de ensino.

Além disso, o ensino de geografia que esses professores tiveram em sua formação, parte deles na escola básica, foi fragmentado em temáticas tradicionais (relevo, clima, população etc.) e, na sua formação profissional, tiveram disciplinas específicas tratadas de forma técnica sem relação com o ensino: geomorfologia, geografia urbana, agrária, geologia, geografia do Brasil etc. A maioria confessa que, ao entrar na escola, eles não conseguem relacionar o que aprenderam na universidade com os conteúdos escolares e vários afirmam que fazem como seus antigos professores, se apegam ao livro didático existente na escola. Paula-PB-32 comenta sua formação profissional:

Existe muita diferença entre a universidade privada e a pública, no ensino público se valoriza mais a pesquisa, não se ensina o aluno a ser um professor e sim um pesquisador. Quando ele vai para sala de aula tem muitos problemas, ele não está preparado para se reconhecer e atuar como professor.

Com base nessas questões, considera-se que o controle do tempo-espaço começa por meio da organização curricular. Embora na introdução dos PCN não esteja explícito que o professor deva seguir metodicamente a sua proposta, sabe-se que, no cotidiano do trabalho docente, com várias aulas para ministrar e atividades para organizar, além de outras atribuições administrativas da escola, muitos professores acabam, mesmo não compreendendo o sentido da proposta, colocando-a em prática do seu modo. Alguns professores assumem que, na sala de aula, reproduzem a 
forma tradicional: "é melhor fazer o tradicional bem feito do que querer inovar sem saber” (Fernando-48).

Até a década de 1970, no Brasil, a escola era para poucos, basicamente para a elite. Para a população mais pobre, a escola servia para aprender a ler, escrever e contar (noções elementares de português e matemática). De lá para cá, houve um aumento na quantidade de ofertas de vagas. Após 1970, começa a obrigatoriedade da escola de oito anos, ampliada atualmente para 12 anos (nove para o ensino fundamental e três para o ensino médio). Essas mudanças fomentaram a construção de mais estabelecimentos de ensino e investimento na formação de professores, posto que, o investimento público na formação dos professores foi diminuto até o início de 2000.

Após esse ano, novas políticas foram elaboradas com o intuito de melhorar a formação e, consequentemente, o ensino na escola básica. As políticas envolveram os parâmetros e as diretrizes curriculares criadas pelo governo para orientar os cursos desde a escola básica até a universidade; houve o estabelecimento de piso salarial para os professores; e a instalação de cursos para eles sem curso superior, à distância ou presenciais. Dentre os diversos programas, destaca-se o Plano Nacional de Formação de Professores (Parfor), instituído para formar professores tanto na modalidade presencial como à distância e o Programa Institucional de Iniciação à Docência (Pibid), realizado no interior dos cursos de formação de professores, que visa incentivar estudantes de graduação para escolher a docência, por meio de um conjunto de ações coordenadas, aproximando a universidade da escola básica. No programa, todos os participantes recebem ajuda financeira - bolsa remunerada - para desenvolver o trabalho, envolvendo auxílio ao professor da escola, pesquisa de procedimentos e produção de materiais didáticos, além de convívio com alunos da escola básica, por vezes orientando-os nas suas dificuldades de aprendizado.

\section{Práticas cotidianas no contexto escolar}

Recordar, lembrar é um trabalho. Quantas vezes o professor é colocado no lugar de rememorar? A experiência de ter de pensar sobre sua prática, como ela é efetivamente realizada no cotidiano escolar e, além disso, lembrar como aprendeu durante sua escolarização, acabou confrontando o aprendizado que o professor obteve na escola básica com seu ofício de 
ensinar atualmente. Os depoimentos dos entrevistados demonstram que existe na escola uma divisão de saberes entre os professores e os alunos e entre os próprios alunos, mesmo estando no mesmo nível de escolarização. A valorização da hierarquia, sobretudo separando os que sabem dos que não conseguem aprender, se mantém em várias escolas como prática semelhante. O ideal de um modelo curricular universal parece ser a tônica da escola na modernidade. Paulo-30, confessa que costuma separar os alunos por níveis de aprendizagem da mesma forma como alguns de seus professores faziam com ele quando estudava, e assume que esse procedimento facilita a organização das tarefas de acordo com as dificuldades de cada um. Em seu depoimento, demonstra que vários professores fazem o mesmo, porém relatou que já teve problemas com os pais dos alunos que não concordavam com a sua classificação, e foi advertido pela direção da escola. Para ele, considerar a realidade do aluno é considerar a realidade de um mundo competitivo que ele vai encontrar pela frente, assim não vê problemas em separar os alunos por nível de aprendizagem, pelo contrário, acredita que além de facilitar o trabalho do professor, pode estimular o aluno a melhorar seu desempenho individual. A crença da maioria dos professores é a de que a divisão das turmas, baseada na idade dos alunos, comum nas escolas, leva a organizá-los por nível de aprendizagem. Nessa perspectiva, os conteúdos devem ser os mesmos para todos. Se todo mundo aprender os mesmos conteúdos, fizer as mesmas atividades propostas pelo professor, para um determinado nível escolar, pode passar para outro nível.

O trabalho pedagógico e as atividades dos alunos refletem a sequência de conteúdos a serem ensinados. A ordenação do tempo-espaço revela a estrutura da escola e da sala de aula. Os alunos devem estar sempre ocupados com alguma atividade para evitar a desordem e a dispersão. No cotidiano escolar, o tempo é cronometrado para garantir o bom desempenho dos alunos, e essa organização diz respeito à disciplina, à cadência das atividades, constituindo-se como fator fundamental para a compreensão do processo do trabalho docente. Na sala de aula, o tempo de duração da aula, a organização fragmentada dos conteúdos, o controle e o acompanhamento do ritmo e das atividades dos alunos refletem no trabalho do professor (Pinheiro, 2012).

Pelos depoimentos dos professores, ficou evidente que, de certo modo, suas práticas docentes refletem os modelos de sua escolarização. 
Apesar das diferenças entre eles, considerando a época em que estudaram, existem aspectos na estrutura escolar que permanecem durante anos. O que é específico são as pessoas, a unidade escolar e o lugar em que se localiza a escola. O depoimento de Vanda-51 conjuga visões conceituais atuais com procedimentos tradicionais sobre como trabalhar com a realidade dos alunos:

O professor contextualiza, criando assim a possibilidade de fornecer os meios para que os alunos organizem os dados da realidade e faça as inter-relações. Nessa perspectiva, o professor está partindo de situações concretas e vividas pelos alunos. Os fatos trazidos pelos alunos são mais um subsídio para o professor criar situações nas quais os alunos compreendam e representem os processos de construção do espaço e dos diferentes tipos de paisagens e territórios.

Uma questão apresentada para os entrevistados foi como concebem a rotina das atividades docentes para a aprendizagem dos alunos. Todos os professores consideraram que é uma prática central da escola, acreditam que a rotina constitui papel preponderante para a aprendizagem. Ela está relacionada com o tempo e o ritmo do trabalho e também com a organização do espaço escolar. Na pesquisa, a rotina foi concebida em sua amplitude, pensando-a como a dimensão que organiza o trabalho do professor e das atividades dos alunos no cotidiano escolar, refletindo na sequência dos conteúdos a serem ensinados, na organização temporal da escola, nas lições, na hora das brincadeiras etc. A rotina organiza o tempo-espaço escolar, regulando a própria vida da escola.

Por que muitas crianças e adolescentes ficam na escola de ensino fundamental, (atualmente com nove anos) e termina esta etapa da escolarização sem aprender com profundidade os conteúdos, às vezes, até com dificuldade de ler e escrever? Que tipo de ensino se está praticando? Se um ensino significativo produz aprendizagem, mobiliza busca por conhecimento, deveria, além de contribuir para compreender os conceitos científicos, preparar os alunos para entender os problemas da vida cotidiana?

De alguma forma, os entrevistados, mesmo com varias limitações, tentam manter o controle do seu trabalho. Todos se esforçam para cumprir as metas delineadas pela escola e declaram que conseguem resultados satisfatórios. Também consideram que o maior problema atual é o crescente aumento de responsabilidades atribuídas aos professores. Não é só a estrutura do tempo-espaço da escola que limita sua criatividade, mas 
as inúmeras orientações curriculares que devem conhecer, além de outros problemas que devem resolver no cotidiano da escola como, por exemplo, trabalhar com temáticas sobre sexualidade, inclusão/exclusão social, diversidade cultural, meio ambiente.

Em relação ao ensino de geografia, segundo os professores, esse conjunto de fatores dificulta o desenvolvimento de atividades que levem em conta o lugar de vivência do aluno como conteúdo básico dessa área de conhecimento na educação básica. Embora concordem que as experiências vividas pelos alunos devem ser consideradas, na prática não conseguem organizar seus planos de trabalho com atividades que levem em conta essas experiências.

Das dificuldades apontadas pelos professores, a mais significativa é sair da sala de aula. Eles apontam diversos entraves, como resistência da direção da escola, falta de recursos, sobretudo meios de transportes para a locomoção dos alunos para outros lugares. Mesmo nas escolas que existem bibliotecas, laboratórios, sala de informática, os professores comentam que faltam funcionários especializados para a manutenção e organização desses espaços. Para muitos deles, o que resta é a sala de aula, os livros didáticos enviados pelo governo e sua explicação sobre a matéria.

\section{Considerações finais}

A educação é um fenômeno social e a escola é parte da sociedade, não está acima dela e talvez não tenha poder para transformá-la sozinha, fato são as propostas curriculares que inundam a escola, além das diversas orientações que chegam para os professores discutirem vários temas emergentes como, por exemplo, o respeito à diversidade sexual: enquanto na escola alguns professores buscam trabalhar o respeito e a tolerância, setores ligados às igrejas continuam com posições contrárias e retrógradas, muitas vezes, deliberadamente tentando neutralizar o trabalho do professor.

Também na atualidade, em virtude da complexidade do mundo, aumentaram as atribuições dos professores; além dos conteúdos tradicionais das disciplinais escolares, têm de lidar com outros temas que surgem diariamente no ambiente escolar, como a questão ambiental; o respeito à diversidade; a inclusão; a utilização das novas tecnologias. Contudo, ainda assim, a escola continua sendo importante para a sociedade e apesar de todos os problemas é inegável que hoje o ensino é melhor que antigamente. 
No entanto, embora existam muitas experiências pessoais de professores, de propostas de organização escolar e curricular, ainda permanece a estrutura de controle do tempo-espaço da escola e da aprendizagem baseada na racionalidade técnica e na rigidez disciplinar. É evidente que buscar alternativas para outro formato de ensino compete aos professores e a todos os interessados na educação escolar, porém os geógrafos, por meio dos estudos do espaço geográfico e dos conceitos vinculados a ele (lugar, território, ambiente etc.), podem olhar para o espaço escolar e seu entorno não apenas como um local onde se ensina a disciplina, mas também, como uma temática de estudo e pesquisa.

Por fim, acredito que conhecer a dinâmica do local de atuação é um passo importante para decifrar as relações e interações sociais existentes. Daí a importância da observação dos tempos e espaços e da experiência dos sujeitos que atuam na escola. Durante a experiência, realizada em várias modalidades de ensino, em inúmeros tipos de escolas, os estudos foram organizados considerando os saberes institucionalizados e aqueles provenientes das relações entre os sujeitos e destes com a realidade cotidiana. Também consideramos as relações interpessoais do ensino-aprendizagem de determinados conteúdos e de práticas experenciadas. O estudo dos sentidos e dos significados do local e de suas práticas cotidianas, das histórias de vida dos professores, revelou que o espaço-tempo escolar é mais complexo do que imaginamos. No ordenamento das relações sociais, participam o Estado, a família, a escola, os meios de comunicação e de informação, além de uma pluralidade de organizações de diferentes orientações religiosas e culturais. As diferentes linguagens influenciam os sujeitos. Assim, conhecer as tramas dessas redes e seu entrelaçamento é fundamental para a organização do trabalho escolar. Esse é o desafio de todos os profissionais da educação, desde a educação infantil até a universidade.

\section{Referências}

BORDIEU, P.; PASSERON, J. C. A reprodução: elementos para uma teoria do sistema de ensino. 3. ed. Rio de Janeiro: Editora Francisco Alves, 1992.

BRASIL (Ministério da Educação). Parâmetros Curriculares Nacionais. Brasília: ME. Disponível em: http://portal.mec.gov.br/index.php?option=com_conten t\&view $=$ article\&id=12657\%3Aparametros-curriculares-nacionais-5o-a-8oseries\&catid $=195 \% 3$ Aseb-educacao-basica\&Itemid=859. Acesso em: 25 mar. 2015. 
CANÁRIO, R. A escola tem futuro? Das promessas às incertezas. Porto Alegre: Artmed, 2006.

CAPEL, H. O nascimento da ciência moderna e a América: o papel das comunidades científicas dos profissionais e dos técnicos no estudo do território. Tradução de Jorge U. G. Vilalobos. Maringá: Editora da UEM, 1999.

CAVALCANTI, L. de S. Concepções teórico-metodológicas da geografia escolar no mundo contemporâneo e abordagens no ensino. In: SANTOS, L. L. C. P. et al. (Orgs.). Convergências e tensões no campo da formação e do trabalho docente. Belo Horizonte: Autêntica, 2010.

FREIRE, P. Pedagogia do oprimido. 16. ed. Rio de Janeiro: Paz e Terra, 1983.

LOPES, A. C. M. E. Teorias do currículo. São Paulo: Cortez, 2011.

NUNES, F. G. Professores e Parâmetros Curriculares Nacionais (PCN): como está essa relação? Revista Ra'e ga, v. 24, p. 92-107, 2012. Curitiba, Departamento de Geografia/UFPR. Disponível em: www.geografia.ufpr.br/raega/. Acesso em: 21 mar. 2014.

PINHEIRO, A. C. Lugares de professores: vivências, formação e práticas nos anos iniciais do ensino fundamental. São Paulo: Porto de Ideias, 2012.

SANTOS, M. A natureza do espaço: técnica e tempo, razão e emoção. São Paulo: Hucitec, 1996.

VLACH, V. R. F. Estado-nação, ensino de Geografia, mundialização: alguns desafios para a formação do professor. In: CAVALCANTI, L. S. (Org.). Formação de professores: concepções e práticas em Geografia. Goiânia: Vieira, 2006.

Antonio Carlos Pinheiro - Possui Graduação em Estudos Sociais pela Faculdade de Ciências e Letras de Bragança Paulista e em Geografia pela Pontifícia Universidade Católica de Campinas. Mestrado em Educação pela Pontifícia Universidade Católica de Campinas e Doutorado em Geociências pela Universidade Estadual de Campinas. Possui Pós-doutorado pela Faculdade de Educação da Universidade de São Paulo. Atualmente é Professor da Universidade Federal da Paraíba.

Recebido para publicação em 10 de janeiro de 2015 Aceito para publicação em 13 de fevereiro de 2015 